\title{
Improving Antibacterial Efficiency of Curcumin in Magnetic Polymeric Nanocomposites
}

\author{
Zaynab Sadeghi-Ghadi ${ }^{1}$ Nicki Behjou ${ }^{2} \cdot$ Pedram Ebrahimnejad $^{2,3} \cdot$ Mehrdad Mahkam $^{4} \cdot$ Hamid Reza Goli $^{5}$. \\ Matthew Lam $^{6} \cdot$ Ali Nokhodchi ${ }^{6}$ (I)
}

Accepted: 18 January 2022

(c) The Author(s) 2022

\begin{abstract}
In recent years, resistance to chemical antibiotics, as well as their side effects, has caused a necessity to utilize natural substances and herbal components with antibacterial effects. Curcumin, the major substance of Curcuma longa's rhizome, was used as an antibacterial agent since ancient times. This work aimed to formulate a novel nanocomposite for the delivery of curcumin to overcome orthodox drugs resistance against bacteria and improve its efficacy. To fabricate targeting nanocomposites, first, $\mathrm{Fe}_{3} \mathrm{O}_{4}$ nanoparticles were synthesized followed by coating the obtained nanoparticles using sodium alginate containing curcumin. A 2 by 3 factorial design was tailored to predict the optimum formulation of nanocomposites. Characterization of nanocomposites including particle size, polydispersity index (PDI), zeta potential, entrapment efficiency, and drug loading was performed. The optimum formulation was analyzed by differential scanning calorimetry (DSC), scanning electron microscopy (SEM), Fourier-transformed infrared spectroscopy (FT-IR), and in vitro release study at different pHs. Finally, minimum inhibitory concentration (MIC) and minimum bactericidal concentration (MBC) of samples against seven common bacteria were determined. Results showed that the optimized formulation contained $400 \mathrm{~nm}$ particles with the PDI and zeta potentials of 0.4 and $-58 \mathrm{mV}$, respectively. The optimized formulation with $70 \%$ entrapment efficiency reduced the MIC value 2 to 4 times in comparison with pure curcumin. Results also showed that polymer and drug concentrations can significantly affect entrapment efficiency. In conclusion, the current investigation demonstrated that this magnetic nanocomposite can be applied for the delivery of curcumin.
\end{abstract}

Keywords Curcumin $\cdot$ Nanocomposites $\cdot$ Factorial design $\cdot$ Iron oxide $\cdot$ Alginate $\cdot$ Antibacterial effect

Pedram Ebrahimnejad

pebrahimnejad@mazums.ac.ir

$\checkmark$ Ali Nokhodchi

a.nokhodchi@sussex.ac.uk

1 Department of Pharmaceutics, Faculty of Pharmacy, Alborz University of Medical Sciences, Karaj, Iran

2 Department of Pharmaceutics, Faculty of Pharmacy, Mazandaran University of Medical Sciences, Sari, Iran

3 Pharmaceutical Sciences Research Center, Hemoglobinopathy Institute, Mazandaran University of Medical Sciences, Sari, Iran

4 Chemistry Department, Faculty of Science, Azarbaijan Shahid Madani University, Tabriz, Iran

5 Department of Medical Microbiology and Virology, Mazandaran University of Medical Sciences, Sari, Iran

6 Pharmaceutics Research Laboratory, School of Life Sciences, University of Sussex, Brighton, UK

\section{Introduction}

In the classical oral drug delivery systems, the drug gets absorbed in the gastrointestinal tract and into the circulatory system where it can enter various parts of the body, exerting pharmacological effect at that particular target area. This delivery can influence a wide range of tissues and organs, which includes those that are not intended, leading to potential side effects [1]. Nanotechnology has shown a tremendous and influential field of research for scientists in the last decade due to its potential in reducing side effects and making dose monitoring easier. There are various types of nanocarriers, which fall into two principal classifications of inorganic nanoparticles (e.g., iron oxide, silica, gold, carbon nanotubes, quantum dots) and organic nanoparticles (e.g., liposomes, niosomes, polymers, micelles, dendrimers) [2, 3]. The increase of drug release in target cells, drug solubility, bioavailability, in vivo stability, bio-adhesive and 
mucoadhesive strength along with reduction in undesirable effects, blood, and tissue concentration fluctuations are just a few benefits of using nanotechnology in drug delivery [4-6]

When two or more materials with significantly different morphologies and general physical properties are combined on a macroscopic scale, a composite with distinct characteristics from the individual components is produced. One of the compositions in composites is called the reinforcing phase, which is embedded in another composition called the matrix phase. Composites that have at least one nanometerscale dimension in the reinforcement phase are called "nanocomposite." Nanocomposites can be strengthened by adding particles and fibers to their matrix. The type and amount of the superficial interactions between the matrix and particles have a considerable effect on the different features of nanocomposites such as chemo-physical, optical, electrical, and mechanical properties [7]. There are four types of nanocomposites based on matrix substances: polymer matrix, ceramic matrix, metal matrix, and intermetallic matrix nanocomposites. Polymer matrix nanocomposites (PMNCa) are more appropriate because of their unique chemo-physical and mechanical features. These nanocomposites generally have low weight, high strength, high electrical conductivity along with high chemical resistance and good thermal stability [8].

Polymer hydrogels have three-dimensional networks with different cross-links which can be chemical or physical. These networks can absorb large amounts of water or physiological fluids. Many specific properties of polymer hydrogels such as suitable biocompatibility, water absorption, and the capability of preparation with a wide group of micro-morphologies have allowed their widespread use in many biomedical applications [9]. Nanocomposite hydrogels may be composed of different classes of nanoparticles like ceramic, clay, metal, or metal oxide nanoparticles in a matrix prepared by polymer hydrogel three-dimensional networks. Adding excitable nanoparticles to the hydrogel matrix makes it sensitive to external stimulants like a magnetic field or light irradiation for triggering the targeting application [10]. Generally, magnetic nanoparticles, especially iron oxide nanoparticles, have been investigated numerously in recent decades for targeting drug/gene delivery [11, 12].

Polysaccharides are the most preferable polymers to prepare hydrogels [13]. Natural polymers are highly regarded for their low cost, nontoxicity, biocompatibility, biodegradability, and hydrophilic nature $[14,15]$. The alginate derived from algae has a polysaccharide structure, which is normally applied in the food, cosmetics, textiles, and pharmaceutical industry. An important feature of alginate is its high biocompatibility and biological activity. Alginate is a water-soluble, safe, and non-toxic polysaccharide. Gels of alginate can be prepared using crosslinking agents including bivalent cations like $\mathrm{Ca}^{2+}, \mathrm{Sr}^{2+}$, $\mathrm{Zn}^{2+}, \mathrm{Mn}^{2+}, \mathrm{Cu}^{2+}$, and $\mathrm{Ba}^{2+}$. These interesting features have attracted researchers to use sodium alginate as a novel carrier for the delivery of bioactive agents $[16,17]$.

The increase in resistance to antimicrobial orthodox drugs and their side effects have caused a serious need for attention to natural sources with antibacterial properties in recent years. There are many alternatives, and natural remedies are one of the potential solutions. Plants are a potential source of antibacterial agents. Herbal extracts can be used as an effective alternative treatment in infectious diseases or as preservatives in foods against both bacterial and fungal microorganisms $[18,19]$.

It has been established that in the past, turmeric was used to treat many diseases and illnesses, particularly in the management of pain and inflammation. The major active component of interest in turmeric is the bright yellow curcumin (a bis- $\alpha, \beta$-unsaturated $\beta$-diketone) that has been used in the treatment of oxidative conditions, inflammatory diseases, various cancers, and bacterial and fungal infections [20].

Curcumin is a plant-derived polyphenolic active ingredient with broad-spectrum antibacterial properties that inhibits bacterial growth due to its structural properties and production of antioxidant products. Curcumin inhibits bacterial virulence factors and bacterial biofilm formation, and also prevents bacterial adhesion to host receptors through the bacterial quorum regulator. Curcumin acts as a light sensitizer under blue light to induce phototoxicity and inhibit bacterial growth [21].

Although there are numerous studies on targeted delivery of curcumin, based on our bibliography, there were no reports for targeting curcumin using iron oxide-entrapped alginate nanoparticles which is the main focus of this study [22-24]. The purpose of the current investigation is to introduce a novel approach to replace or provide an alternative to the conventional antibiotics that commonly show serious adverse drug reactions and drug resistance due to their non-targeting, toxicity, and insufficient permeability. The present study seeks to fabricate a new formulation with the use of a natural substance and safe additive, which have an emerging outline to decrease the dose of curcumin compared to the conventional dosage forms.

In the current study, curcumin-loaded magnetic nanocomposites with alginate were fabricated. These magnetic nanocomposites can be administered orally and controlled by an external magnet. Different formulations were prepared and analyzed by differential scanning calorimetry (DSC), scanning electron microscopy (SEM), and Fourier transform infrared spectroscopy (FT-IR). In vitro release studies in 2 different pHs $(1.2,7.4)$ were also studied. Finally, the antibacterial effects such as minimum inhibitory concentration (MIC) and minimum bactericidal concentration $(\mathrm{MBC})$ of the samples were evaluated on seven common bacteria. 


\section{Materials and Methods}

Iron (III) chloride (Samchun, Seoul, Republic of Korea), iron (II) chloride (TetraChem, Ingersoll, Canada, Tween 80 (Samchun Pure Chemical Co. Ltd., Korea), sodium alginate, methanol (Fluka, Sigma-Aldrich, Buchs, Switzerland), curcumin, calcium chloride, and ethanol (Merck KGaA, Madrid, Spain) were used in this study.

\section{Synthesizing Magnetic Nanoparticles}

The co-precipitation technique was used to prepare iron oxide nanoparticles $\left(\mathrm{Fe}_{3} \mathrm{O}_{4}\right)$ using ferric and ferrous chloride in anaerobic conditions at room temperature. Different concentrations of $\mathrm{FeCl}_{2} \cdot 4 \mathrm{H}_{2} \mathrm{O}(2-7 \mathrm{~g})$ and $\mathrm{Fe}^{2+}$ (0.01-0.035 mol) were used to prepare iron oxide nanoparticles $\left(\mathrm{Fe}_{3} \mathrm{O}_{4}\right)$, while concentrations of $\mathrm{FeCl}_{3} \cdot 6 \mathrm{H}_{2} \mathrm{O}(11.6 \mathrm{~g})$ and $\mathrm{Fe}^{3+}(0.04 \mathrm{~mol})$ were constant as shown in Table 1. In brief, a solution of ferric chloride was prepared by dissolving $11.6 \mathrm{~g}$ of ferric chloride in $200 \mathrm{ml}$ double-distilled water, by deoxygenation under continuous purging of nitrogen gas. Then, ferrous chloride solution was prepared by dissolving a specified amount of ferrous chloride in $100 \mathrm{ml}$ of doubledistilled water. The water was deoxygenated by nitrogen purging. After mixing the two solutions, the resultant solution was stirred fast $(900 \mathrm{rpm})$ under the nitrogen gas. During heating of the mixture to $85^{\circ} \mathrm{C}, 40 \mathrm{ml}$ of $\mathrm{NH}_{4} \mathrm{OH}$ was added drop-wise. The color of the solution changed due to the precipitation of $\mathrm{Fe}_{3} \mathrm{O}_{4}$ within the flask. This color change was considered as the endpoint of iron oxide formation. The reaction was refluxed at $80^{\circ} \mathrm{C}$ for $60 \mathrm{~min}$. The solution was allowed to cool at room temperature for $4 \mathrm{~h}$, followed by separating the precipitates using a strong magnet $(1.3 \mathrm{~T})$ along with the collection of the supernatant for electrical conductometry. After washing the sample with distilled water three times, it was then rinsed with acetone to remove unreacted reagents. The procedure was followed by drying the nanoparticles at $25^{\circ} \mathrm{C}$ under vacuum conditions [25]. Finally, the best formulation was selected, which was determined by the color of the dispersion before precipitation of nanoparticles (as black color of dispersion is a characteristic parameter for the dominant presence of $\mathrm{Fe}_{3} \mathrm{O}_{4}$ in the dispersion) and measuring the electrical conductivity after the collection of nanoparticles.

\section{Preparation of Nanocomposites Using 2 by 3 Factorial Design}

In this study, a 2 by 3 factorial design was used to determine the best formulation and analyze the effect of different parameters on the properties of magnetic nanocomposites. Three factors, 2 levels, and 8 runs were used in this 2 by 3 factorial statistical design. Different independent variables containing alginate concentration $(\mathrm{mg} / \mathrm{ml})$, sonication time (min), and curcumin concentration $(\mathrm{mg} / \mathrm{ml}$ ) were selected to evaluate their effects on dependent variables such as particle size, polydispersity index (PDI), zeta potential, encapsulation efficiency (EE), and drug loading (DL) of the magnetic nanocomposites. Based on the authors' previous experience, they believed that the selected variables could have a significant effect on the properties of the nanocomposites. Therefore, alginate concentration $(\mathrm{g} / \mathrm{ml})$ was selected to study its effect on zeta potential and stability of the nanocomposites; sonication time ( $\mathrm{min}$ ) was selected to study its effect on the size of the nanocomposites, and curcumin concentration $(\mathrm{mg} / \mathrm{ml})$ was selected to study its effect on the entrapment efficiency and drug loading on the nanocomposites. The polynomial equation was generated by this experimental design (using Statgraphic graphic centurion C18 and Design-Expert 10.0. 7) as follows:

$Y_{i}=b_{0}+b_{1} A+b_{2} B+b_{3} C+b_{12} A B+b_{13} A C+b_{23} B C$

$Y_{i}$ is the dependent variable; $b_{0}$ is the intercept; $b_{1}$ to $b_{23}$ are the regression coefficients, and $A, B$, and $C$ are the independent variables that were selected from the preliminary experiments.

Table 1 Physicochemical characteristics of iron oxide nanoparticles including the amount of iron salts and properties of each formulation $($ mean $\pm \mathrm{SD}, n=3)$

\begin{tabular}{llllllllll}
\hline $\begin{array}{l}\text { Formulation } \\
\text { code }\end{array}$ & $\begin{array}{l}\mathbf{F e C l}_{2} \cdot \mathbf{4} \mathbf{H}_{2} \mathbf{O} \\
(\mathbf{g})\end{array}$ & $\mathbf{F e}^{2+}(\mathbf{m o l})$ & $\mathbf{F e C l}_{3} \mathbf{6 H} \mathbf{H}_{2} \mathbf{O}(\mathbf{g})$ & $\mathbf{F e}^{3+}(\mathbf{m o l})$ & Color & $\begin{array}{l}\text { Electrical } \\
\text { conduction } \\
(\boldsymbol{\mu s} / \mathbf{c m})\end{array}$ & Size (nm) & $\begin{array}{l}\text { PDI* } \\
\text { Zeta potential } \\
(\mathbf{m v})\end{array}$ \\
\hline$F_{1}$ & 2 & 0.010 & 11.6 & 0.04 & Blue & $91 \pm 1.51$ & $375 \pm 9.78$ & $0.3 \pm 0.03$ & $-18 \pm 2.63$ \\
$F_{2}$ & 3 & 0.015 & 11.6 & 0.04 & Green & $78 \pm 3.18$ & $410 \pm 10.83$ & $0.4 \pm 0.21$ & $-14 \pm 4.87$ \\
$F_{3}$ & 4 & 0.020 & 11.6 & 0.04 & Green-black & $60 \pm 1.13$ & $450 \pm 3.52$ & $0.3 \pm 0.09$ & $-23 \pm 3.75$ \\
$F_{4}$ & 5 & 0.025 & 11.6 & 0.04 & Black & $33 \pm 2.34$ & $390 \pm 14.76$ & $0.2 \pm 0.56$ & $-20 \pm 1.63$ \\
$F_{5}$ & 6 & 0.030 & 11.6 & 0.04 & Black & $31 \pm 1.45$ & $510 \pm 5.96$ & $0.2 \pm 0.31$ & $-24 \pm 0.98$ \\
$F_{6}$ & 7 & 0.035 & 11.6 & 0.04 & Brown & $54 \pm 3.32$ & $510 \pm 5.68$ & $0.5 \pm 0.17$ & $-21 \pm 2.32$ \\
\hline
\end{tabular}

*Polydispersity index 
According to Table 2, independent variables $A, B$, and $C$ were alginate concentration $(\mathrm{g} / \mathrm{ml})$, sonication time $(\mathrm{min})$, and curcumin concentration $(\mathrm{mg} / \mathrm{ml})$, respectively. Two levels $(-1$ and +1$)$ were selected for independent variables. Responses as dependent variables were Y1 (Particle size), Y2 (PDI), Y3 (Zeta potential), Y4 (\% EE), and Y5 (\% DL).

Briefly, the intended amount of alginate was dissolved in distilled water $(30 \mathrm{ml})$. Curcumin solution $(4 \mathrm{ml}$ of specified concentration) was dropped into the alginate solution under vigorous stirring. The obtained mixture was covered up with the aluminum sheet and was refluxed for $3 \mathrm{~h}$. $\mathrm{Fe}_{3} \mathrm{O}_{4}$ nanoparticle $(0.06 \mathrm{~g}$ previously dispersed in a water-ethanol solution consisting of $3 \mathrm{ml}$ of ethanol and $3 \mathrm{ml}$ of distilled water via bath-sonication for $15 \mathrm{~min}$ ) was then dropped into the alginate-curcumin solution under severe stirring. The well-dispersed mixture was dropped into the aqueous solution of calcium chloride (1:100,000 alginate concentration) through a $0.3-\mathrm{mm}$-syringe needle from $20 \mathrm{~cm}$ height at a constant rate under intense stirring. Finally, the resultant formulation was ultra-sonicated (BANDELIN, Germany) for the intended time [25]. A summary has been shown in the flow chart (Fig. 1).

\section{Particle Size, PDI, and Zeta Potential}

The particle size of magnetic nanocomposites and the dispersity of the particles were measured by the dynamic light scattering (DLS) method. The Zeta-sizer (Nano ZA, Malvern Instruments, UK) was used for measuring particle size, polydispersity index, and zeta potential of the magnetic nanocomposites. The angle of detection was $90^{\circ}$, the temperature was $25^{\circ} \mathrm{C}$, the concentration of the samples used for analysis was 20-400 kilo counts per second (KCPS), and the intensity of diffraction was 100,000 counts per second.
Zeta potential was determined in the same manner by Zetasizer (Nano ZA, Malvern Instruments, UK).

\section{Entrapment Efficiency}

To obtain the entrapment efficiency (EE) of curcumin, the nanocomposites were placed in ultracentrifugation for 40 min with $35,329 \times$ g force (HERMLE, Z36HK, Germany), and the absorbance of curcumin in the supernatant (free drug) was taken by UV-Visible spectrophotometry at $428 \mathrm{~nm}$. The entrapment efficiency percentage was determined using Eq. 2:

$\mathrm{EE}(\%)=\frac{W_{\text {(initialdrug) }}-W_{\text {(freedrug) }}}{W_{\text {(initialdrug) }}} \times 100$

$W_{\text {(initial drug) }}$ : initially added curcumin

$W_{\text {(free drug) }}$ : curcumin in supernatant

To measure the percentage of the drug-loaded in nanocomposites, purified curcumin-loaded nanocomposites were dried for $24-48 \mathrm{~h}$ in the oven at $40{ }^{\circ} \mathrm{C}$. Then, the dried nanocomposites were dissolved in pure acetone, and the solution was filtered through a $0.2-\mu \mathrm{m}$ filter. Finally, the solution absorbance was measured spectrophotometrically at $428 \mathrm{~nm}$. The drug loading percentage capacity was then calculated using Eq. 3:

$\% \mathrm{DL}=\frac{\text { Mass of curcumin in nano composite }(\mathrm{mg})}{\text { Mass of nano composite recovered }(\mathrm{mg})} \times 100$

where the mass of nanocomposite recovered includes the mass of nanocomposites containing alginate, iron oxide, and curcumin.
Table 2 Factorial design (2 by 3 ) experimental design with measured responses $($ mean $\pm \mathrm{SD}, n=3$ )

\begin{tabular}{lllllllll}
\hline $\begin{array}{l}\text { Formulation } \\
\text { code }\end{array}$ & $\mathbf{A}$ & $\mathbf{B}$ & $\mathbf{C}$ & Size $(\mathbf{n m})$ & PDI* & $\begin{array}{l}\text { Zeta potential } \\
(\mathbf{m v})\end{array}$ & $\mathbf{E E} * *(\%)$ & $\mathbf{D L}^{* * *}(\%)$ \\
\hline$F_{1}$ & 1 & 1 & -1 & $413.83 \pm 5.22$ & $0.35 \pm 0.03$ & $63.1 \pm 1.82$ & $23.68 \pm 1.62$ & $9.87 \pm 1.09$ \\
$F_{2}$ & 1 & -1 & 1 & $517.80 \pm 1.91$ & $0.40 \pm 0.04$ & $65.03 \pm 0.38$ & $55.85 \pm 1.79$ & $10.93 \pm 1.68$ \\
$F_{3}$ & -1 & -1 & 1 & $398.37 \pm 9.46$ & $0.44 \pm 0.08$ & $61.17 \pm 3.31$ & $76.83 \pm 1.96$ & $25.58 \pm 4.69$ \\
$F_{4}$ & -1 & 1 & 1 & $325.57 \pm 3.37$ & $0.38 \pm 0.04$ & $55.67 \pm 3.63$ & $75.78 \pm 0.39$ & $15.41 \pm 0.97$ \\
$F_{5}$ & -1 & -1 & -1 & $382.00 \pm 5.80$ & $0.40 \pm 0.02$ & $66.43 \pm 1.23$ & $54.17 \pm 2.51$ & $9.37 \pm 1.08$ \\
$F_{6}$ & 1 & 1 & 1 & $502.43 \pm 2.00$ & $0.35 \pm 0.01$ & $68.33 \pm 0.31$ & $47.11 \pm 5.19$ & $22.95 \pm 0.9$ \\
$F_{7}$ & -1 & 1 & -1 & $275.17 \pm 2.76$ & $0.35 \pm 0.02$ & $49.83 \pm 1.55$ & $51.57 \pm 4.88$ & $7.42 \pm 3.38$ \\
$F_{8}$ & 1 & -1 & -1 & $493.03 \pm 7.57$ & $0.4 \pm 0.05$ & $58.47 \pm 1.07$ & $28.89 \pm 3.90$ & $7.47 \pm 0.72$ \\
\hline
\end{tabular}

Independent variables $A, B$, and $C$ are alginate concentration $(\mathrm{mg} / \mathrm{ml})$, sonication time (min), and curcumin concentration $(\mathrm{g} / \mathrm{ml})$ respectively

*Polydispersity index

**entrapment efficiency

***drug loading 
Fig. 1 The nanocomposite synthesis flowchart

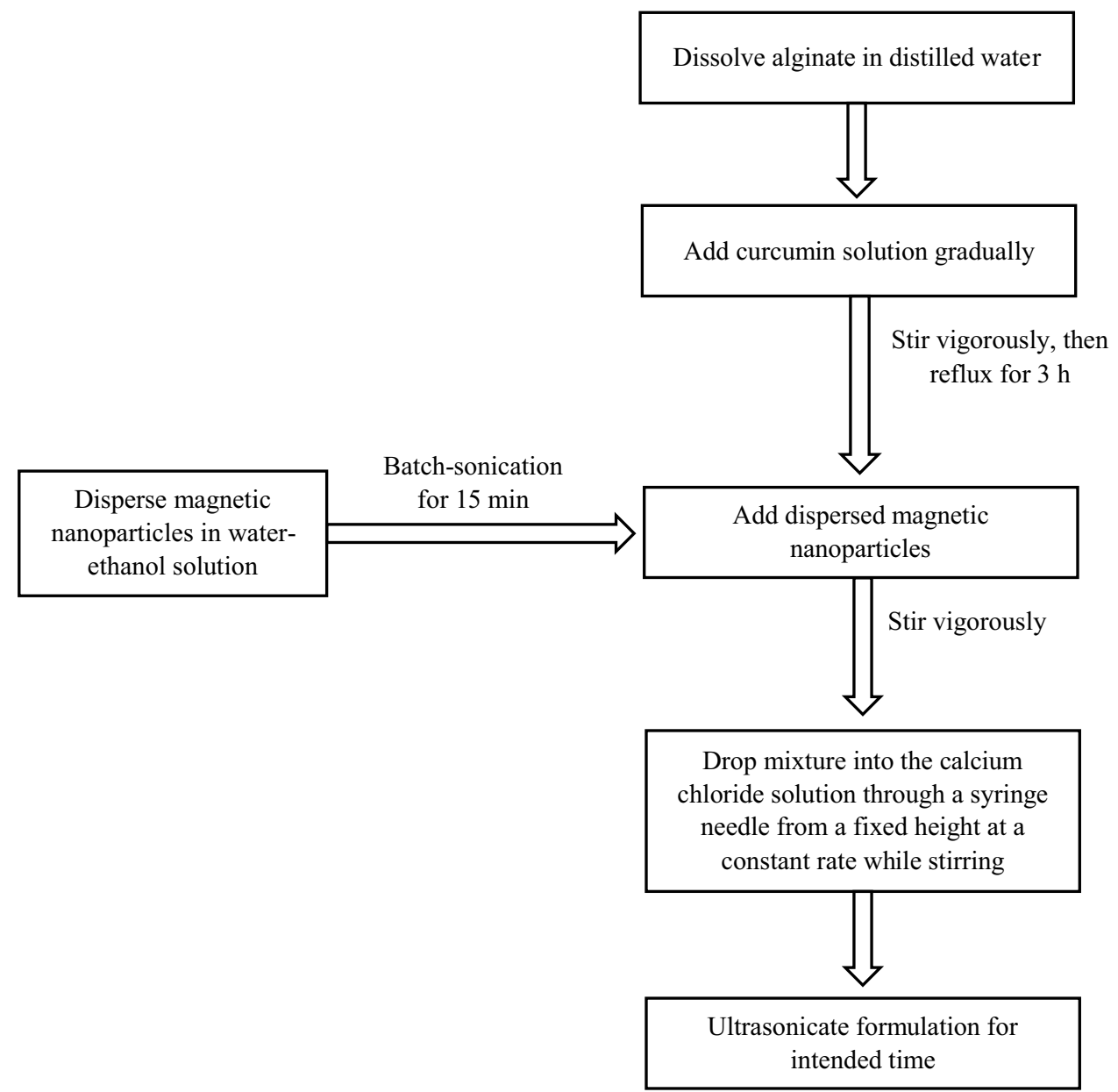

\section{In Vitro Release Study}

To prepare sink condition for in vitro release study, a saturation solubility test was performed to obtain the solubility of curcumin in different dissolution media such as dissolution media with $\mathrm{pH} 1.2$, pH 1.2 plus 10\%w/v PEG, pH 1.2 plus $0.1 \%$ w/v Tween $80, \mathrm{pH} 7.4$, $\mathrm{pH} 7.4$ plus $10 \%$ w/v PEG, and $\mathrm{pH} 7.4$ plus $0.1 \% \mathrm{w} / \mathrm{v}$ Tween 80 , before the in vitro release study. In fact, curcumin saturated solubility was assessed to calculate sink conditions. Briefly, excess amounts $(1 \mathrm{~g})$ of pure curcumin were added to $10 \mathrm{ml}$ of different media with different $\mathrm{pHs}$ in an aluminum-covered 15-ml falcon tube. Then, these tubes were placed in an orbital shaker incubator at $37{ }^{\circ} \mathrm{C}$ at $120 \mathrm{rpm}$ for $48 \mathrm{~h}$ to ensure saturation. After the equilibrium solubility was attained, the absorbance of the saturated solution was analyzed by a UV-Vis spectrophotometer at $428 \mathrm{~nm}$.

For the release test, the dialysis bag (MWCO 12,400, sigma, USA) containing $1 \mathrm{ml}$ of nanocomposite dispersion was placed in a $25-\mathrm{ml}$ falcon tube containing $20 \mathrm{ml}$ of release medium under sink condition (USP standard buffer at $\mathrm{pH} 1.2$ (simulated gastric fluid) and $\mathrm{pH} 7.4$ (simulated small intestinal fluid) with $0.1 \% \mathrm{w} / \mathrm{v}$ Tween 80 based on saturation solubility test data). Falcons were covered by an aluminum sheet and were kept in an orbital shaker incubator at $37{ }^{\circ} \mathrm{C}$ at $120 \mathrm{rpm}$ for $48 \mathrm{~h}$. Samples $(3 \mathrm{ml})$ were taken at a pre-determined time. In order to maintain the sink condition, $3 \mathrm{ml}$ of fresh medium was added to the test medium. Medium absorbance was analyzed using UV-Vis spectrophotometry at $428 \mathrm{~nm}$ to quantify the amount of drug in the medium. The drug release experiments were conducted in triplicate $(n=3)$.

Different kinetic models were studied to analyze drug release profiles including zero-order, 3rd root of mass, HixsonCrowell, first-order, Higuchi, nonconventional order 1, Peppas (Power Law), square root of mass, Weibull, nonconventional order 2, linear probability, log probability, and reciprocal powered time. Determination of the square of correlation coefficients ( $r^{2}$ values) and mean percentage error (MPE) results were used as critical parameters to select the best-fitted model $[26,27]$.

\section{SEM}

The nanocomposite dispersion was ultra-centrifuged three times with $35,329 \times \mathrm{g}$ force for $40 \mathrm{~min}$. Precipitated 
nanocomposites were then washed with purified water. After freezing the washed precipitated nanocomposites at $-70{ }^{\circ} \mathrm{C}$, it was freeze-dried for $24 \mathrm{~h}$ (CHRIST alpha 1-2, Germany). The dried nanocomposites were coated with gold before examining using scanning electron microscopy (SNE4500M, USA).

\section{FT-IR Analysis}

The optimized formulation was dried by a freeze-dryer to get a powdered form of the formulation for FT-IR study. The obtained powders of nano-magnetic composites, alginate, and curcumin were mixed with $\mathrm{KBr}$ individually. After mixing with $\mathrm{KBr}$, the powder was pressed to get a disk $(13 \mathrm{~mm})$. The obtained disk was used for FT-IR analysis using Perkin Elmer FT-IR spectrophotometer (Perkin FTIR-One, USA) from 400 to $4000 \mathrm{~cm}^{-1}$.

\section{DSC}

DSC (Pyris 6, PerkinElmer, USA) was used to evaluate the thermal behaviors of specimens. A certain amount of each sample (about $5 \mathrm{mg}$ ) was used in the DSC analysis. Samples were placed in the hermetic crimped aluminum pans. The DSC pan containing the sample was heated ranging from 30 to $300{ }^{\circ} \mathrm{C}$ under $\mathrm{N}_{2}$ atmosphere at a scanning rate of $10{ }^{\circ} \mathrm{C} /$ $\min$.

\section{Antimicrobial Analysis}

Antibacterial susceptibility test was performed according to CLSI guidelines. Microbial suspensions of Staphylococcus aureus (ATCC:29,213), Enterococcus faecalis (ATCC:29,212), Pseudomonas aeruginosa (ATCC:27,853), Acinetobacter baumannii (ATCC:19,606), Escherichia coli (ATCC:25,922), Klebsiella pneumonia (ATCC:700,603), and Proteus mirabilis (ATCC:25,933) were prepared in sterilized physiological solution to reach a concentration of bacterial cells of $10^{8} \mathrm{CFU} / \mathrm{ml}$ ( $0.5 \mathrm{McFarland}$ turbidity). Minimum inhibitory concentration (MIC) tests were carried out using 96-well plates. Each well contained $100 \mu \mathrm{L}$ Mueller-Hinton broth. The stock solutions of pure curcumin and nanocomposite with and without curcumin were diluted, and $100 \mu \mathrm{L}$ of each diluted solution was transferred into the first well of each row. Then, serial dilutions were performed to obtain final concentrations of $3.9-2000 \mu \mathrm{g} / \mathrm{ml}$ for pure curcumin and nanocomposites containing curcumin. Nanocomposite without curcumin was used at final concentrations of $13.76-7000 \mu \mathrm{g} / \mathrm{ml}$. Control wells contained no antibacterial agent.

Finally, $100 \mu \mathrm{L}$ of the bacterial suspensions was added to all wells, and plates were incubated at $37{ }^{\circ} \mathrm{C}$ for $48 \mathrm{~h}$. MIC is the lowest concentration of the antibacterial agent that inhibits the visible growth of the bacteria, which can be deduced by the clarity of the sample. Wells without growth were selected to culture on the blood agar plates followed by incubating the plates overnight at $37^{\circ} \mathrm{C}$ to determine the MBC. MBC is defined as the lowest concentration of the test compounds that reduces bacterial growth by $\geq 99.9 \%$.

\section{Results and Discussion}

\section{Magnetic Nanoparticles}

As shown in Table 1, six formulations were prepared with different amounts of iron salts. Two critical parameters were used to select the best formulation based on the color of the dispersion before nanoparticle sedimentation and supernatant electrical conduction after nanoparticle collection. The formulation with the highest amount of $\mathrm{Fe}_{3} \mathrm{O}_{4}$ and the lowest size of the particles was selected as the best formulation (Table 1). The black color of the dispersion is an indicator of the presence of $\mathrm{Fe}_{3} \mathrm{O}_{4}$. There were two formulations $\left(F_{4}\right.$ and $F_{5}$ ) that had black coloration. Between these formulations, $F_{4}$ with $5 \mathrm{~g}$ of $\mathrm{FeCl}_{2} \cdot 4 \mathrm{H}_{2} \mathrm{O}$ and $0.025 \mathrm{~mol}$ of $\mathrm{Fe}^{2+}$ had a smaller particle size. Therefore, $F_{4}$ was used for preparing magnetic alginate nanoparticles for further investigation. Magnetic nanoparticles are used to treat many diseases such as cancer, tissue, and nerve inflammation and bacterial infections [28-31]. These drug delivery systems can be affected by an external magnetic field and induce hyperthermia, which is considered a thermal strategy in cancer therapy. These drug delivery systems also can enhance treatment efficiency. Magnetic nanoparticles not only can be used as a therapeutic drug delivery but also as a diagnostic strategy. Magnetic nanoparticles especially iron nanoparticles have been used to detect gram-positive and gram-negative bacteria in other studies [31-33].

\section{Data Analysis}

To determine the effect of selected variables and achieve the best formulation, a 2 by 3 factorial experimental design with 3 independent variables at 2 different levels was used.

According to Figs. 2 and 3 and Table 2, the average size of the nanocomposites was in the range of 275 to $517 \mathrm{~nm}$. It was noted that two formulations of the nanocomposites had $z$ average (average size) smaller than iron oxide nanoparticles. This might be due to the fact that alginate nanoparticles might be also formed separately during the preparation of nanocomposites. Since $z$ average only shows the mean particle size of the dispersion, if the contribution of alginate nanoparticles (which could be much smaller than iron oxide nanoparticles) in the system is higher than the contribution of nanocomposites and iron oxide particles, then the overall 

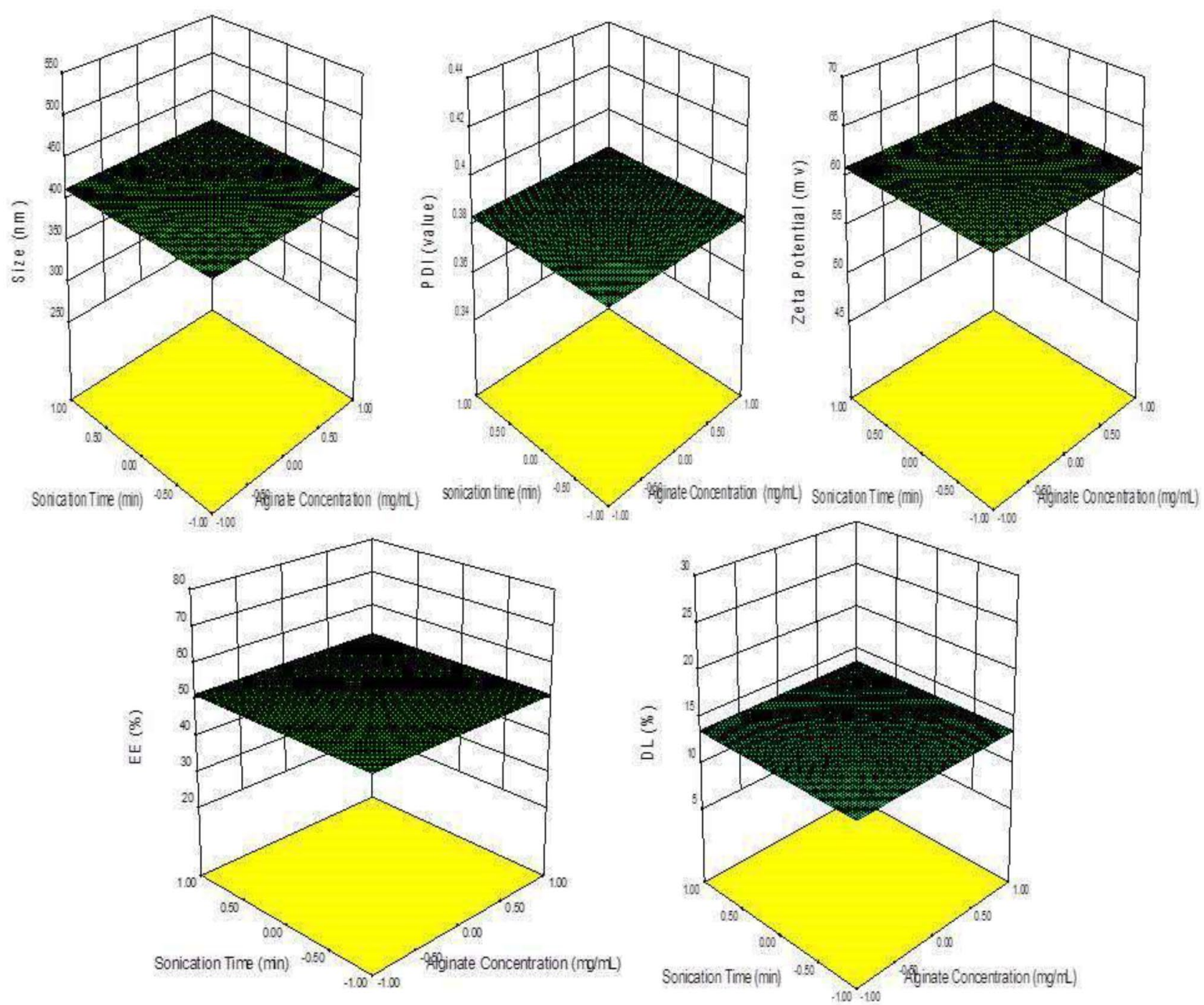

Fig. 2 Estimated response surface 3D plots for 5 responses

average particle size of the system could be smaller than the size of iron oxide particles. The particle size (dependent variable) obtained at various levels of the 3 independent variables (A, B, and C) was subjected to multiple regressions to yield the best polynomial equation (full model): by increasing the amount of alginate [34]. This result could be due to the fact that by increasing alginate concentration, the amount of alginate, which is available for preparing the shell of $\mathrm{Fe}_{3} \mathrm{O}_{4}$ nanoparticles (core), would be increased; thus, the thickness of the shell and the size of the particles

Particle size $=413.525+68.2475 A-34.275 B+22.5175 C+10.6325 A B+5.825 A C+12.2325 B C$

Among the 3 independent variables, variable $A$ (alginate concentration $(\mathrm{mg} / \mathrm{ml}))$ with a $p$-value of $0.0347, F$-ratio of 335.68 , and mean absolute error of 3.725 was the only variable with a $p$-value lower than 0.05 , indicating that just this variable is significant in predicting particle size. According to the Pareto chart in Fig. 3, positive effect was seen between alginate concentration and the size of the nanocomposite. The sizes of the nanocomposites were increased would be increased accordingly. Moreover, the particle size Pareto chart showed a negative effect between particle size and sonication time. Particle size was decreased by increasing sonication time. For instance, the size of the particles decreased from $398.37 \mathrm{~nm}\left(F_{3}\right)$ to $325.57 \mathrm{~nm}\left(F_{4}\right)$. The same is true when the particle size of $F_{8}$ and $F_{1}$ or $F_{2}$ and $F_{6}$ was compared. But it was not statistically significant with a $p$-value of 0.0689 . 

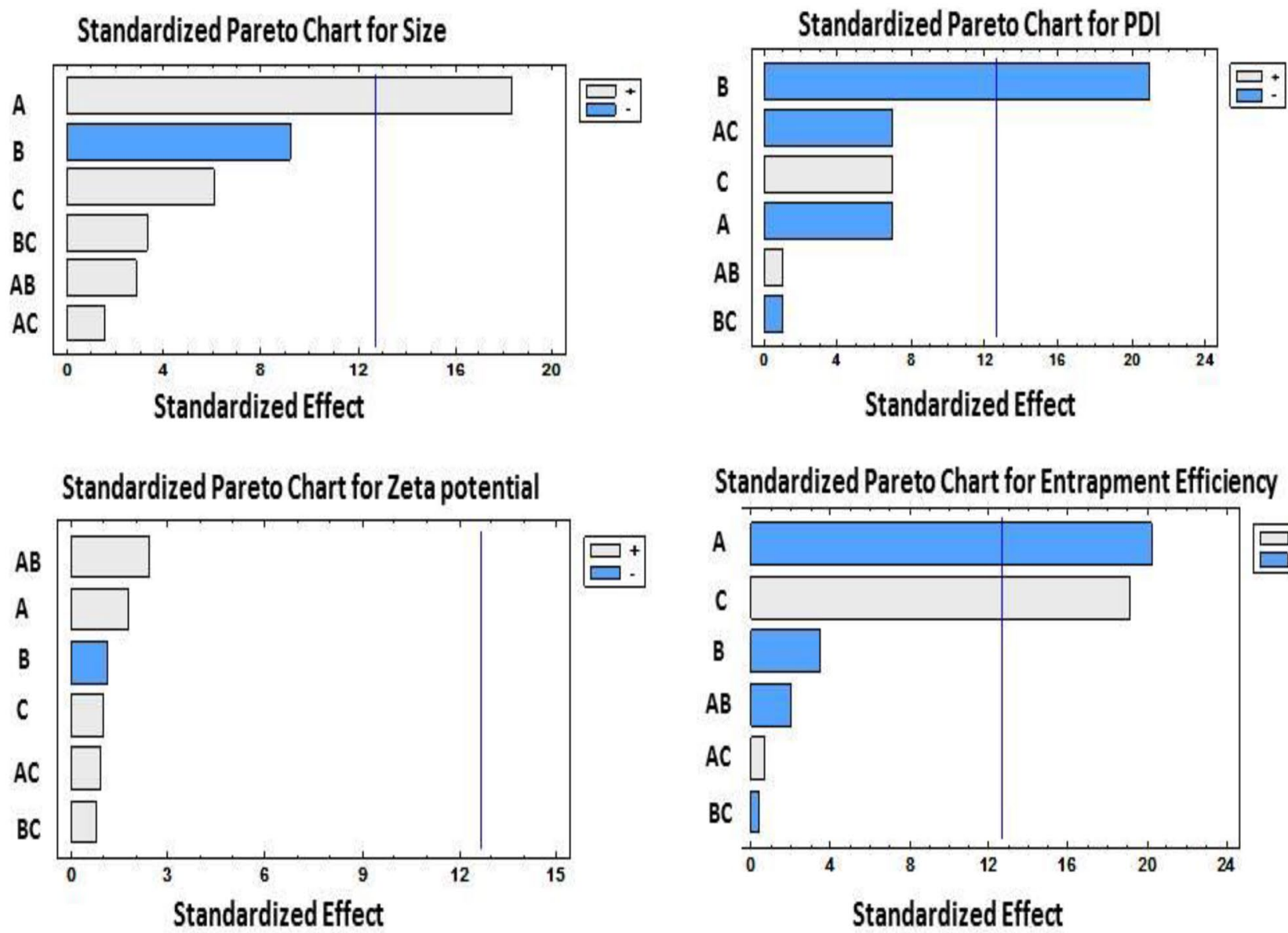

Standardized Pareto Chart for Entrapment Efficiency

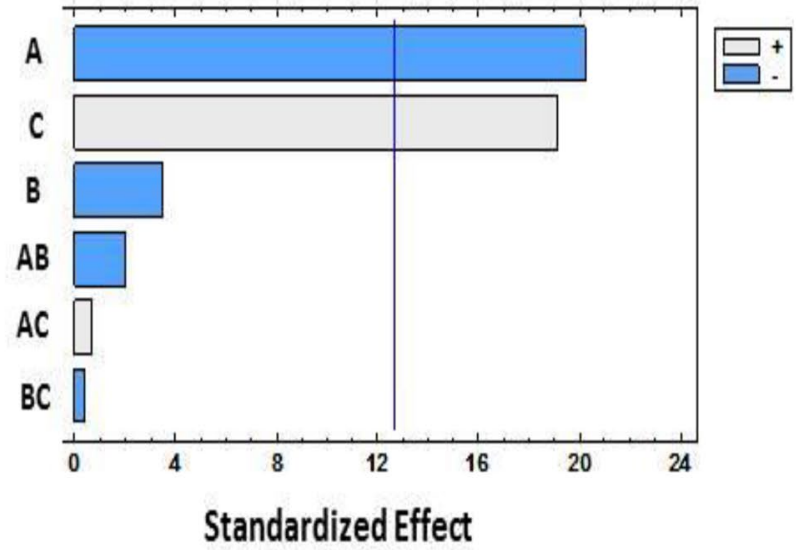

Standardized Pareto Chart for Drug Loading

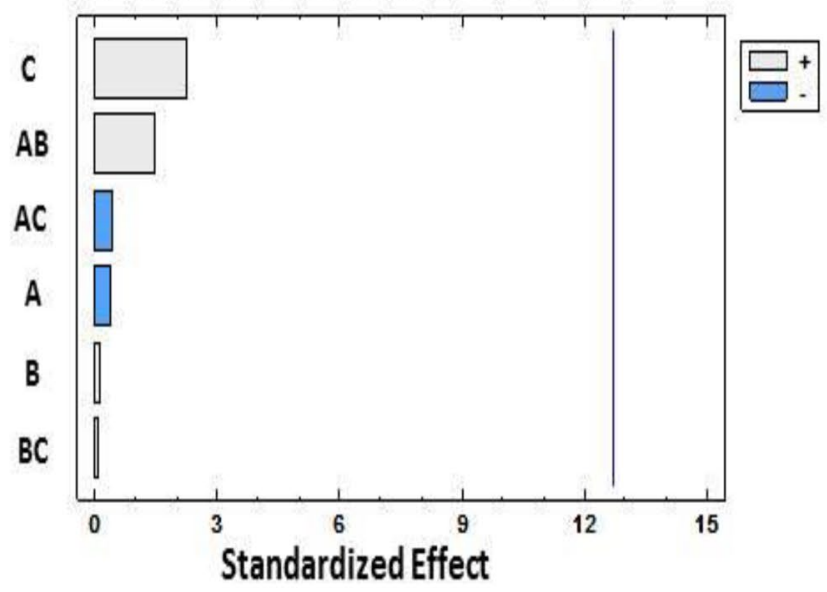

Fig. 3 Standardized Pareto charts for 5 responses (PDI is polydispersity index)

Polynomial model was also developed for PDI value:

$0.030, F$-ratio of 441 , and mean absolute error of 0.00125 .

$P D I=0.38375-0.00875 A-0.02625 B+0.00875 C+0.00125 A B-0.00875 A C-0.00125 B C$

According to the Pareto chart for PDI (Fig. 3), sonication time was the only independent variable that had a significant effect on the dispersity index with a $p$-value of
This effect was negative. On the other hand, by increasing sonication time, the polydispersity index was decreased, and the homogeneity of the dispersion was increased 
(Fig. 2; Table 2) [35]. This result might be due to the effect of sonication on the reduction of aggregation of particles, hence increasing the homogeneity of the dispersion. The effect of the other independent variables including alginate and curcumin did not show statistical significance. of entrapment. While the effect of alginate concentration on the entrapment efficiency was negative, it means that the entrapment efficiency was decreased by increasing the amount of alginate [37].

Finally, the polynomial equation for the last dependent variable $(\% \mathrm{DL})$ is obtained as follows:

$\% D L=13.6255-0.82075 A-0.28725 B+5.09225 C+3.3175 A B-0.957 A C+0.1755 B C$

Polynomial model for zeta potential was as follows:

Zeta potential $=61.0037+2.72875 A-1.77125 B+1.54625 C+3.75375 A B+1.40125 A C+1.22125 B C$

Zeta potential is a critical parameter in nanoparticle dispersion to predict dispersion stability. In fact, the high value of zeta potential (positive or negative charge) is an indicator of stable dispersion. Although the value of zeta potential in all stable nano-dispersions is not the same, there is no defined range for zeta potential values to be used as an indicator for a stable nano-dispersion. Most published papers are in agreement that zeta potential above $20 \mathrm{mv}$ can guarantee stable nano-dispersion [36]. In this study, the values of zeta potential in different formulations were in the range of 49-68 mv, indicating a stable dispersion.

According to Figs. 2 and 3, alginate concentration could have a positive effect on the value of zeta potential, but the $p$-value is 0.3295 , indicating this effect is not considered statistically significant.

The polynomial model for entrapment efficiency was as follows:
Analysis of variance for DL yields show that none of the independent variables had a significant effect on DL with $p$-values of $0.7755,0.9184$, and 0.2627 for alginate concentration $(\mathrm{mg} / \mathrm{ml})$, sonication time $(\mathrm{min})$, and curcumin concentration $(\mathrm{mg} / \mathrm{ml})$ respectively. According to Pareto chart (Fig. 3), variable $A$ (alginate concentration) had a negative effect on drug loading that might be due to the fact that drug loading is the ratio of the weight of the entrapped curcumin to the weight of the nanocomposites. As nanocomposites also contain alginate, by increasing the amount of alginate in the formulation, the amount of alginate that could be coated on the iron oxide increases and the weight of the nanocomposites can increase accordingly. This can lead to a reduction in the drug loading percentage. But, the entrapment efficiency percentage (EE\%) decreases by increasing the concentration of alginate as the entrapment efficiency is the ratio of the amount of entrapped curcumin to the amount of the initial curcumin used in the process.

$\% E E=51.7345-12.8525 A-2.1995 B+12.157 C-1.2875 A B+0.44 A C-0.247 B C$

Formulations 3 and 4 had the highest EE (>75\%), and $F_{3}$ had the highest DL (> 25\%). The standardized effect of the independent variables and their interaction on \% $\mathrm{EE}$ was investigated by the Pareto chart (Fig. 3). This chart shows the main effect of the independent variables and their interactions with their relative significance on the EE. The length of each bar in the chart indicates the standardized effect of that factor on the response. The fact that the bars for $A$ (alginate concentration in $\mathrm{mg} / \mathrm{ml}$ ) and $C$ (curcumin concentration in $\mathrm{mg} / \mathrm{ml}$ ) extend beyond the reference line (Fig. 3) indicates that $\mathrm{EE}$ is significantly dependent on both alginate and curcumin concentrations. Curcumin concentration had a positive effect on entrapment efficiency. By increasing the amount of curcumin, the amount of entrapment efficiency increased. This result could be due to the fact that by increasing the independent variable $C$ (curcumin concentration in $\mathrm{mg} / \mathrm{ml}$ ), the amount of curcumin that is available for entrapment would increase, and this could increase the probability

\section{Optimum Formula}

According to the experimental results, and the effect of independent variables on the responses, the level of variables was determined by a computer optimization process ( 2 by 3 factorial design) that suggests the optimal response. The optimum formulation is the one that gives a low value for both particle size and PDI and high values of zeta potential, \%EE, and \%DL. Using a computer optimization process, levels of $-0.140544,1$, and 0.999 for $A$, $B$, and $C$ were predicted, respectively and the theoretical values of $Y_{1}$ to $Y_{5}$ for the best or optimum formulation predicted by the 2 by 3 factorial design (Table 3 ). According to Table 3, all observed values were in close agreement with the theoretical values, except for PDI.

Results indicate that the measured dependent values were as expected. Measured dependent values were compared with the predicted ones, and relative errors were 
Table 3 Predicted versus visual values for dependent variables in optimum formulation

\begin{tabular}{llllll}
\hline Response & Prediction & Lower 95\% limit & Upper 95\% limit & Visual value & Relative error \% \\
\hline Size $(\mathrm{nm})$ & 402.1 & 306.7 & 497.5 & 399.5 & 0.63 \\
PDI & 0.37 & 0.34 & 0.40 & 0.40 & 8.11 \\
Zeta potential $(\mathrm{mV})$ & -60.9 & 21.1 & 100.7 & -59.80 & 1.79 \\
EE $(\%)$ & 63.37 & 47.11 & 79.63 & 71.876 & 9.79 \\
DL & 18.96 & -38.11 & 76.05 & 20.01 & 5.48 \\
\hline
\end{tabular}

measured; the differences were found to be insignificant. Therefore, it can be judged that this mathematical equation is valid to predict the experiment.

\section{In Vitro Drug Release}

The plot of mean percentage release versus time is shown in Fig. 4. The optimum formulation produced an initial burst release in $\mathrm{pH}=1.2$, which more than $60 \%$ of the drug was released within the initial sampling time $(1 \mathrm{~h})$. It can be seen that there was approximately $97 \%$ drug release from nanoparticles in all $2 \mathrm{pH}$ values over $26 \mathrm{~h}$.

The in vitro release profiles were fitted to various kinetic models to determine the mechanism of drug release. The dissolution rate constants were calculated from the slope of the respective plots, and different models were correlated for each $\mathrm{pH}$ (Table 4).

Based on Table 4, the difference between the Higuchi and Hixon-Crowell model is extremely small at low $\mathrm{pH}$. This addresses the possibility of a surface erosion mechanism at both pHs. Even though the Higuchi model has a higher R-squared, the Hixon-Crowell model has a lower mean prediction error at both $\mathrm{pH}$ values, and it makes more sense physically for these particles.

It seems that curcumin burst release can be explained by curcumin absorption and loading at the surface of the nanoparticles. Among three different $\mathrm{pHs}$, the initial drug release was more rapid in the acidic $\mathrm{pH}$ (about 60\%) than the other pHs, which is supported by the results of the study on dextran sulfate-chitosan nanoparticles containing curcumin by Anitha et al. [38].

The correlation coefficient $\left(r^{2}\right)$ values in $\mathrm{pH} 1.2$ show that the appropriate model for curcumin release from nanoparticles was Higuchi models described by Eq. 9:

$M_{t} / M_{\infty}=k_{H} t^{1 / 2}$

where $M_{t} / M_{\infty}$ is the drug fraction released in time $t$, and $k_{H}$ is the Higuchi dissolution constant. Higuchi describes the behavior of a dispersed drug from a homogeneous matrix whose release is controlled by solvent infusion to the matrix, and the release mechanism is demonstrated by the Fickian diffusion.

It was noted that when $\mathrm{pH}$ was increased to $\mathrm{pH} 7.4$, the best model to fit the release data was Hixon-Crowell model (Eq. 10):

$\left(M_{\infty}\right)^{1 / 3}-\left(M_{t}\right)^{1 / 3}=k_{H C} t$

Hixon-Crowell model is developed for erosion-release mechanism. In this model, drug release is dependent on both dissolution rate and surface changes or erosions, and diffusion is not the important factor in this model, unlike the Higuchi equation.

On the other hand, it can be comprehended from Fig. 4 that the slope of the chart in $\mathrm{pH} 1.2$ is not higher than other $\mathrm{pH}$ that shows more rapid concentration changes in 7.4.
Fig. 4 In vitro release profile of curcumin from optimized nanoparticles in different media $(n=3)$

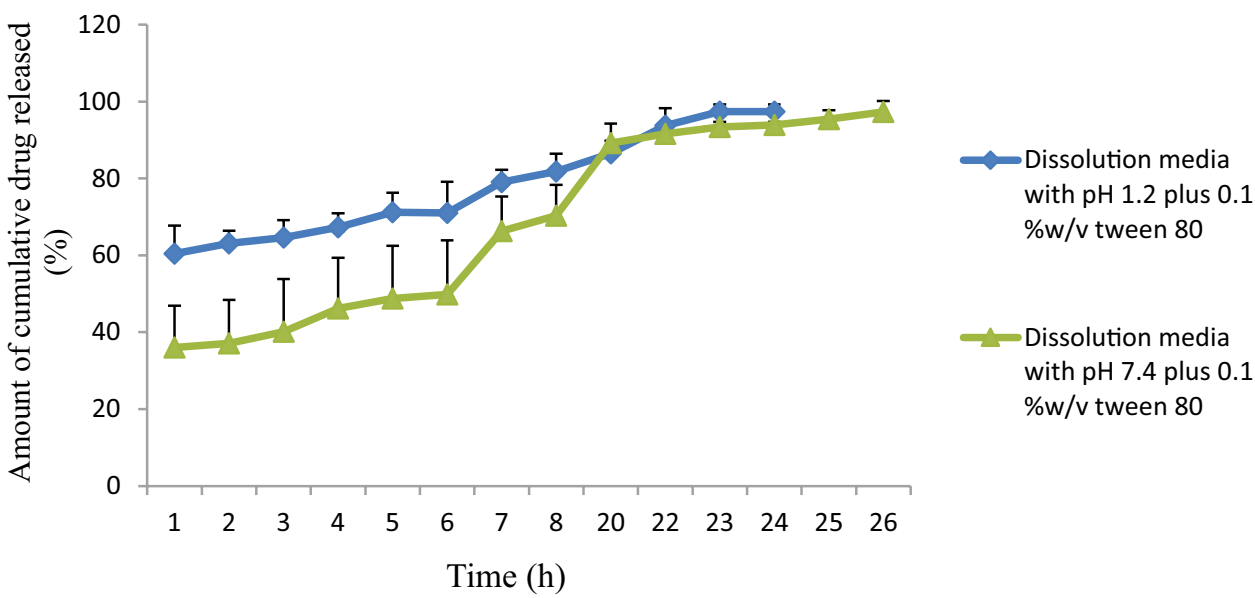


Table 4 Fitting parameters of the release data to various release kinetic models

\begin{tabular}{|c|c|c|c|c|c|c|}
\hline \multicolumn{7}{|l|}{$\mathrm{pH}=1.2$} \\
\hline Kinetic Models & MPE \% & RSQ & $\mathbf{K}$ & $\mathbf{n}$ & Slope & intercept \\
\hline Zero order & 3.62 & 0.924 & 0.0144 & & 0.014 & 0.628 \\
\hline First order & 2.99 & 0.888 & 0.1046 & & -0.105 & -0.736 \\
\hline Higuchi & 2.72 & 0.954 & 0.0934 & & 0.093 & 0.504 \\
\hline Hixon-Crowell & 2.70 & 0.926 & & & 0.017 & 0.252 \\
\hline Square root of mass & 3.08 & 0.935 & & & 0.018 & 0.367 \\
\hline Three seconds root of mass & 3.35 & 0.937 & & & 0.018 & 0.468 \\
\hline Weibull & 5.52 & 0.856 & 0.4404 & 0.440 & 0.440 & -0.361 \\
\hline Linear Probability & 2.77 & 0.922 & 0.0649 & & 0.065 & 0.222 \\
\hline Log-Probability & 7.05 & 0.816 & & & 0.529 & -0.116 \\
\hline Reciprocal powered time & 8.25 & 0.780 & & & -0.987 & 0.331 \\
\hline Non-conventional order 1 & 3.54 & 0.932 & 0.0161 & 0.150 & 0.016 & 0.562 \\
\hline Non-conventional order 2 & 3.60 & 0.865 & 0.021 & 1.143 & 0.021 & 0.096 \\
\hline \multicolumn{7}{|l|}{$\mathrm{pH}=7.4$} \\
\hline Zero order & 7.08 & 0.946 & 0.0241 & & 0.024 & 0.379 \\
\hline First order & 6.05 & 0.975 & 0.1136 & & -0.114 & -0.188 \\
\hline Higuchi & 5.51 & 0.972 & 0.1606 & & 0.161 & 0.163 \\
\hline Hixon-Crowell & 4.70 & 0.986 & & & 0.021 & 0.109 \\
\hline Square root of mass & 4.89 & 0.982 & & & 0.025 & 0.179 \\
\hline Three seconds root of mass & 5.62 & 0.973 & & & 0.026 & 0.249 \\
\hline Weibull & 8.24 & 0.929 & 0.1634 & 0.711 & 0.711 & -1.288 \\
\hline Linear Probability & 4.81 & 0.980 & 0.0849 & & 0.085 & -0.412 \\
\hline Log-Probability & 12.20 & 0.902 & & & 0.756 & -0.937 \\
\hline Reciprocal powered time & 13.60 & 0.886 & & & -1.329 & 1.633 \\
\hline Non-conventional order 1 & 6.41 & 0.960 & 0.0251 & 0.150 & 0.025 & 0.323 \\
\hline Non-conventional order 2 & 8.01 & 0.961 & 0.021 & 1.143 & 0.021 & 0.010 \\
\hline
\end{tabular}

As $\mathrm{pH}$ decreases, the alginate gel shrinkage increases as reported previously by You, J.-O. et al. [39].

At high pHs, the negative charge in the matrix increased because of carboxyl group dissociation in the alginate chains that relaxes the net-like structure of the beads. In fact, the protonation of carboxyl groups in the alginate chains and establishing alginic acid cause the increase in hydrophobicity and the decrease in solubility that leads to an enhancement in the viscosity of the alginate solution in the acidic $\mathrm{pH}$ region. Based on the above description, and according to the current release results, the Higuchi model (Fickian diffusion) can be simply described by the high shrinkage and viscosity of alginate gel in acidic conditions [39].

It can be concluded from the research published by You et al. that at higher $\mathrm{pH}$ levels, alginic acid is more hydrophilic and is in a highly swollen state. At pHs above 7.0, the net-like structure of alginic acid becomes loose and hydrophilic, therefore having a larger volume. Thus, drugs can be released from the net-like structure of alginic acid faster compared to when low $\mathrm{pH}$ was employed. This is in agreement with the results of the current study (curcumin released rate in non-acidic $\mathrm{pH}$ was dependent on dissolution and surface changes or erosions, and the best-fitted model at pH 7.4 was Hixon-Crowell model) [17].

\section{Scanning Electron Microscopy}

According to Fig. 5, nanocomposites were spherical, and the size of the particles was $359 \mathrm{~nm}$ that was in good correlation with the size reported by DLS $(399.53 \pm 5.44 \mathrm{~nm})$. Smaller particles were also seen in this figure that can be well explained by the value of PDI $(0.49 \pm 0.06)$.

\section{FT-IR Studies}

To investigate the interactions and probable bonding between the drug and carrier, FT-IR spectra were evaluated between 400 and $4000 \mathrm{~cm}^{-1}$ (Fig. 6). The main IR band assignments of pure curcumin were $\mathrm{OH}$ (phenolic) stretching vibration (wavenumber $3509 \mathrm{~cm}^{-1}$ ), $\mathrm{C}=\mathrm{O}$ stretching vibration of the carbonyl group (wavenumber $1628 \mathrm{~cm}^{-1}$ ), $\mathrm{C}=\mathrm{C}$ (aromatic) stretching vibration (wavenumber $1601 \mathrm{~cm}^{-1}$ ), $\mathrm{C}=\mathrm{C}$ (olefinic) stretching vibration (wavenumber $1509 \mathrm{~cm}^{-1}$ ) and -O- stretching vibration of the ether group (wavenumber $1026 \mathrm{~cm}^{-1}$ ). The main IR band assignments 
Fig. 5 Scanning electron micrograph of curcumin entrapped optimized nanocomposites

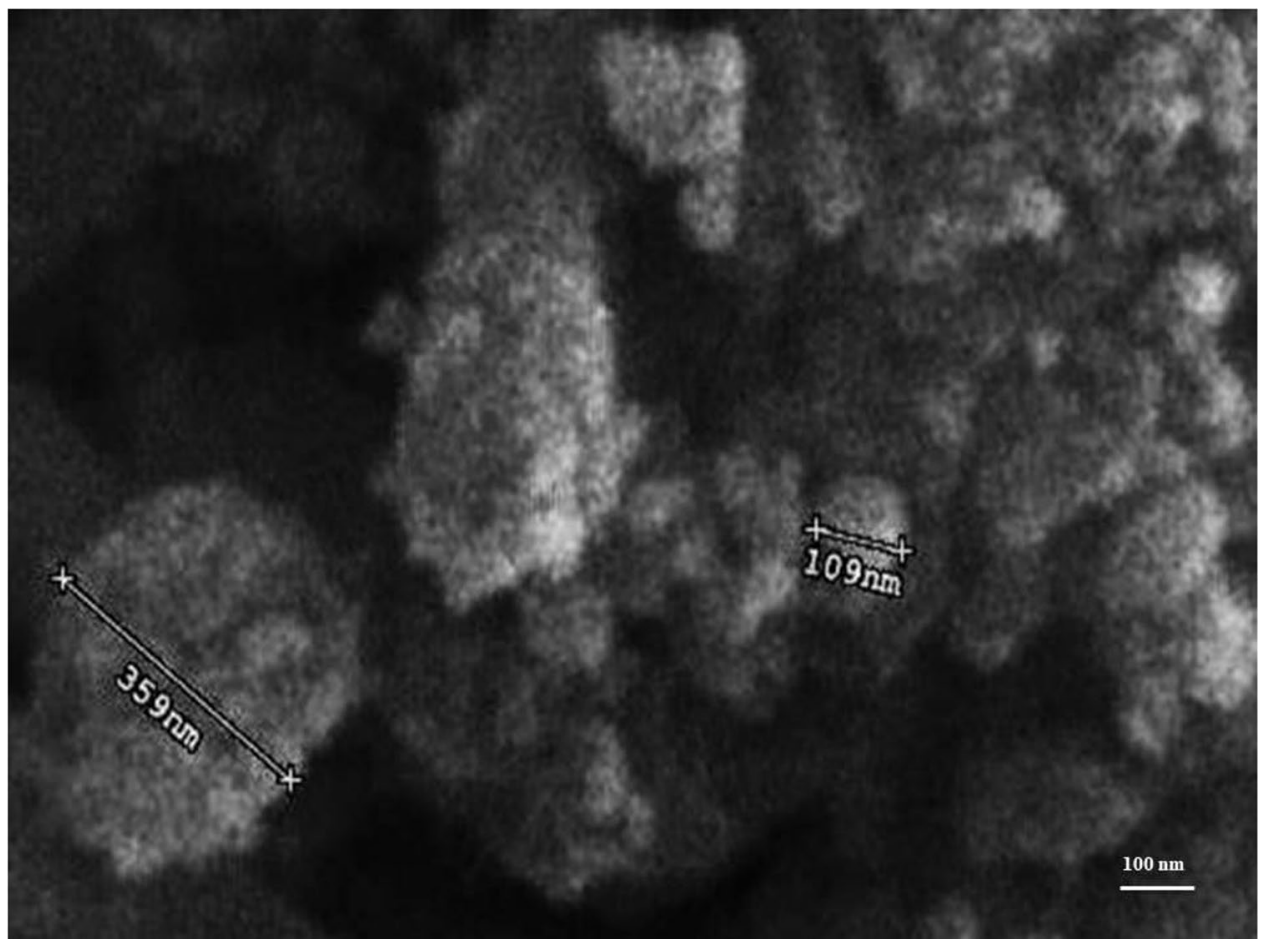

of pure sodium alginate were $\mathrm{OH}$ stretching vibration (wavenumber $3409 \mathrm{~cm}^{-1}$ ), $\mathrm{COOH}$ symmetric stretching vibration of the carboxylic group (wavenumber $1607 \mathrm{~cm}^{-1}$ ), $\mathrm{COOH}$ asymmetric stretching vibration of the carboxylic group (wavenumber $1425 \mathrm{~cm}^{-1}$ ), C-H aliphatic stretching vibration (wavenumber $2924 \mathrm{~cm}^{-1}$ ), -O- stretching vibration of the cyclic ether group (wavenumber $1028 \mathrm{~cm}^{-1}$ ), and $\mathrm{Fe}-\mathrm{O}-\mathrm{Fe}$ stretching vibration of the $\mathrm{Fe}_{3} \mathrm{O}_{4}$ nanoparticles (wavenumber $588 \mathrm{~cm}^{-1}$ ).

The FT-IR spectrum of the curcumin-sodium alginate nanocomposites was different from that of the pure ones. By comparing the spectra of pure sodium alginate with the nanocomposites, the absorption peaks at $3409 \mathrm{~cm}^{-1}$ and $1607 \mathrm{~cm}^{-1}$ characteristics for $-\mathrm{OH}$ and $\mathrm{C}=\mathrm{O}$ groups stretching vibrations shifted to a $3401 \mathrm{~cm}^{-1}$ and $1602 \mathrm{~cm}^{-1}$ in the nanocomposite, respectively. This result reflects the alginate-calcium complex formation and cross-linking. Moreover, the FT-IR spectrum of the nanocomposite showed the indicator peaks of curcumin and sodium alginate. Meanwhile, the presence of $\mathrm{Fe}_{3} \mathrm{O}_{4}$ magnetic nanoparticles is demonstrated by the strong stretching absorption peak at $575 \mathrm{~cm}^{-1}$ which is the diagnostic peak for $\mathrm{Fe}-\mathrm{O}$ bond [40]. The FT-IR spectra demonstrate that there is no chemical interaction between sodium alginate and curcumin loaded in the nanocomposite.

\section{DSC Analysis}

In Fig. 7A, an endothermic peak at $180.84{ }^{\circ} \mathrm{C}$ was seen that was due to the melting of the pure curcumin. In Fig. 7B, two different peaks were seen. An endothermic peak at $129.23^{\circ} \mathrm{C}$ could be due to the melting of alginate, and an exothermic peak at $248.79{ }^{\circ} \mathrm{C}$ may be due to the decomposition of alginate [41]. In Fig. 7C DSC thermogram of the physical mixture of curcumin, alginate and magnetic nanoparticles were shown. An endothermic peak of curcumin and two different peaks of alginate can be seen in this thermogram, indicating that curcumin and alginate did not interact. In Fig. 7D, the DSC thermogram of curcumin-entrapped nanocomposites was shown. According to this thermogram, the characteristic peak of curcumin disappeared, which might be due to the entrapment of curcumin in the alginate nanoparticles containing magnetic nanoparticles and molecular dispersion of curcumin in the nano-composites. Characteristic peaks of alginate were seen in this thermogram that could be due to the shell position of the alginate. The DSC thermogram of the curcumin entrapped nanocomposites shows depression of the alginate melting peak, which suggests that the curcumin is dispersed within the alginate matrix, but this is not considered as an interaction between curcumin and alginate which was also proved by the FTIR results. The DSC thermogram of magnetic nanoparticles in Fig. 7E showed no distinctive peak [36].

\section{In Vitro Antibacterial Activity}

The antibacterial activity of pure curcumin, nanocomposites without curcumin, and curcumin-entrapped nanocomposites against different bacteria was analyzed (Table 5). 


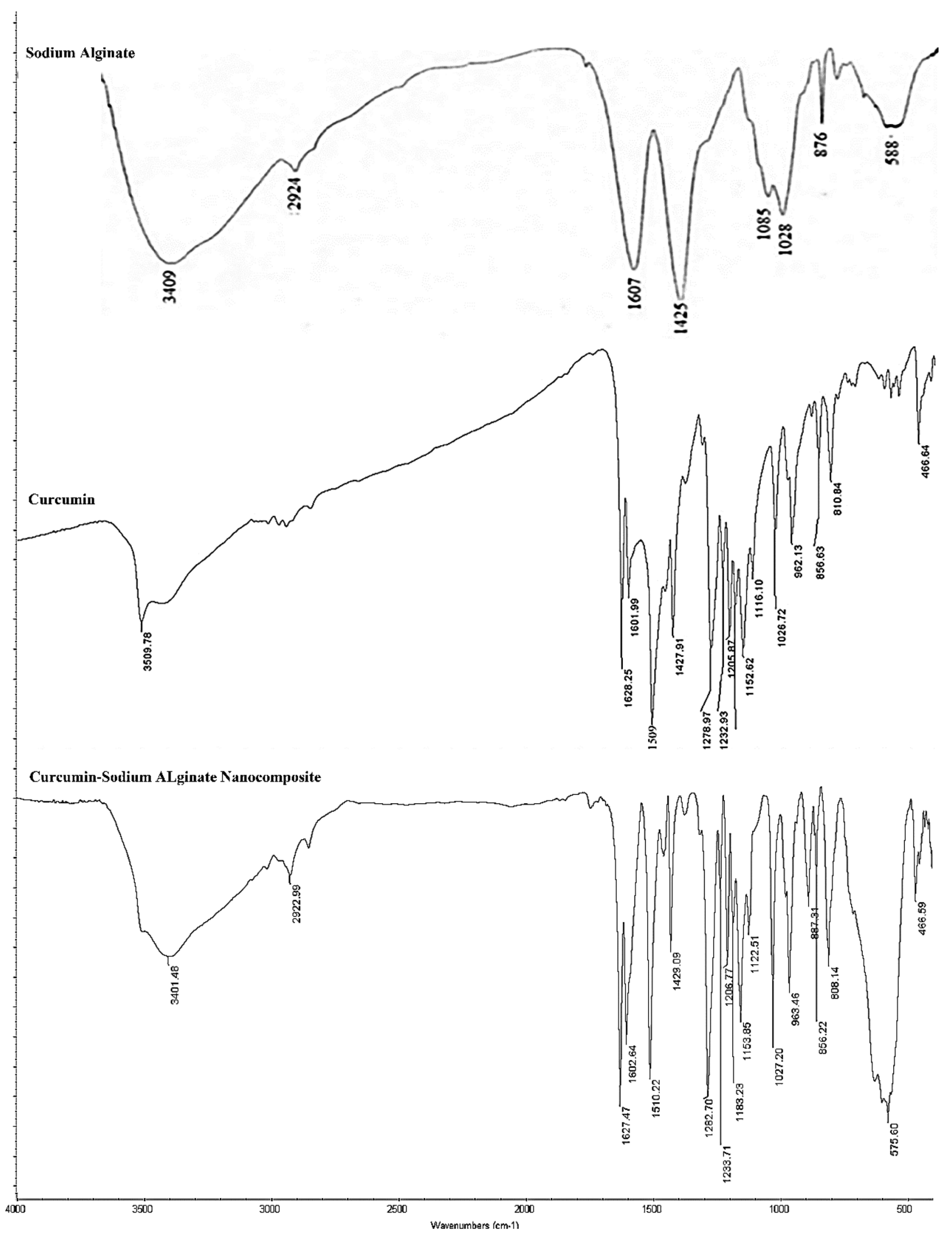

Fig. 6 FT-IR spectrum of sodium alginate, curcumin and optimized nanocomposites 


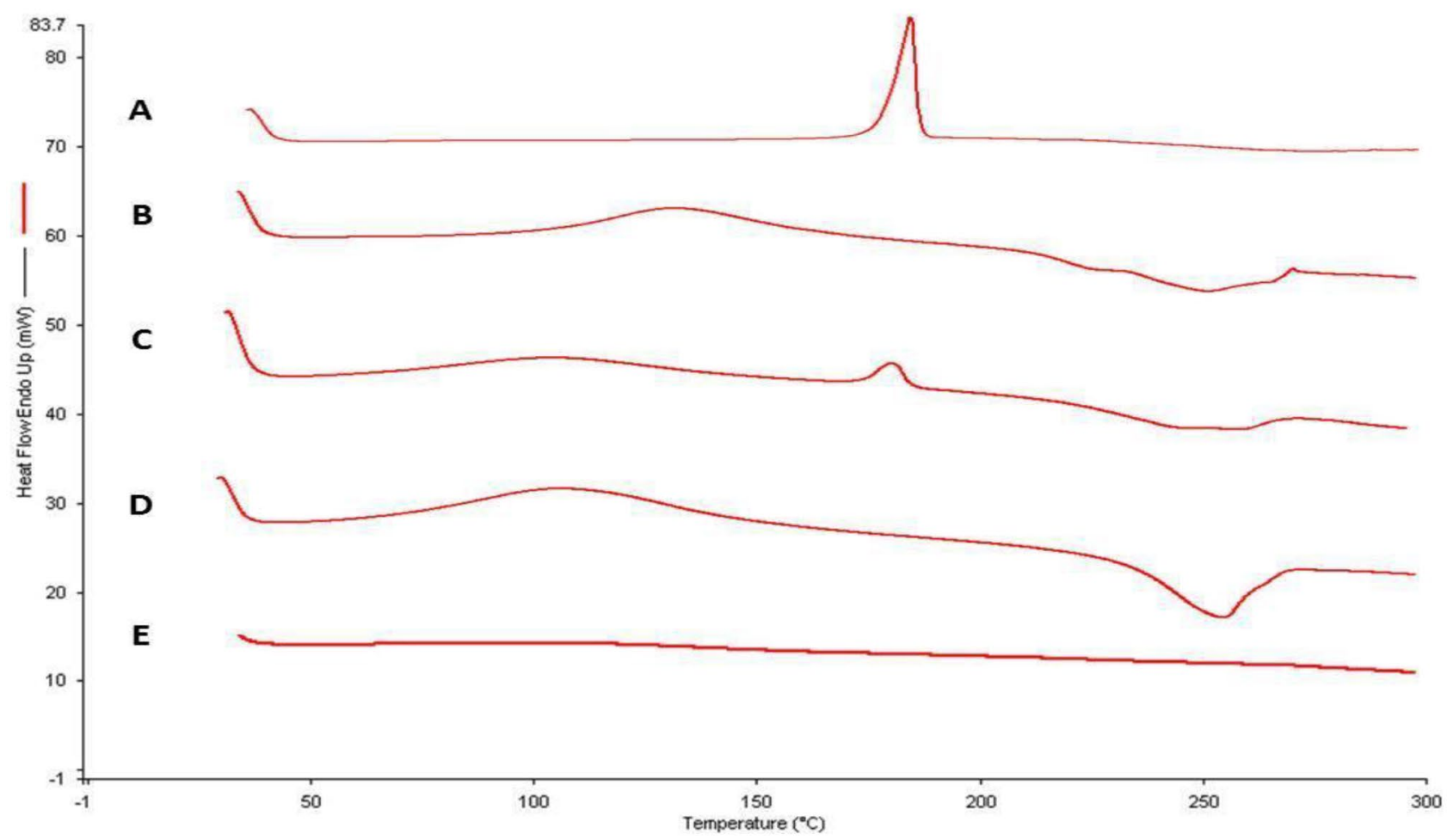

Fig. 7 DSC thermograms of pure curcumin (A), alginate (B), physical mixture (C), curcumin entrapped nanocomposites (D), magnetic nanoparticles $(\mathbf{E})$ with heat flow endothermic up

Curcumin-entrapped nanocomposites showed a higher antibacterial effect in comparison with pure curcumin and nanocomposite without curcumin. Briefly, in the cases of Escherichia coli, Klebsiella pneumonia, and Proteus mirabilis, MIC values for curcumin entrapped in nanocomposite were 4 and 14 times lower compared to pure curcumin and nanocomposites without curcumin respectively. In addition, in Staphylococcus aureus, Enterococcus faecalis, Pseudomonas aeruginosa, and Acinetobacter baumannii, MIC values were 2 and 14 times lower when curcumin entrapped in nanocomposite was used to compare pure curcumin and nanocomposites without curcumin respectively. MIC values of curcumin entrapped nanocomposites against all bacteria were lower than MIC values of pure curcumin and nanocomposite without curcumin (Table 5). In fact, preparing the nanostructure to deliver curcumin can significantly improve its antimicrobial effect [42].

Curcumin-entrapped nanocomposites also showed the highest antibacterial effect against Staphylococcus aureus with an MIC value of $15.62 \mu \mathrm{g} / \mathrm{ml}$. MBC values of this nanocomposite against all bacteria were stable at $500 \mu \mathrm{g} /$ $\mathrm{ml}$. That was higher than the MBC values of pure curcumin against Pseudomonas aeruginosa, Escherichia coli, Klebsiella pneumonia, and Proteus mirabilis. According to the results, the preparation of curcumin entrapped nanocomposite improved the antibacterial efficacy of curcumin on
Table 5 The MIC (minimum effective concentration) and MBC (minimum bactericidal concentration) values $(\mu \mathrm{g} / \mathrm{ml})$ of pure curcumin, curcumin entrapped nanocomposites, nanocomposite without curcumin

\begin{tabular}{|c|c|c|c|c|c|c|}
\hline \multirow[t]{2}{*}{ Bacteria } & \multicolumn{2}{|c|}{$\begin{array}{l}\text { Nanocomposite with } \\
\text { curcumin }\end{array}$} & \multicolumn{2}{|c|}{$\begin{array}{l}\text { Nanocomposite } \\
\text { without curcumin }\end{array}$} & \multicolumn{2}{|c|}{ Pure curcumin } \\
\hline & MIC & $\mathrm{MBC}$ & MIC & $\mathrm{MBC}$ & MIC & MBC \\
\hline Staphylococcus aureus & 15.62 & 500 & 875 & 7000 & 31.25 & 500 \\
\hline Enterococcus faecalis & 31.25 & 500 & 875 & 7000 & 62.5 & 500 \\
\hline Pseudomonas aeruginosa & 62.5 & 500 & 875 & 7000 & 125 & 1000 \\
\hline Acinetobacter baumannii & 62.5 & 500 & 875 & 7000 & 125 & 500 \\
\hline Escherichia coli & 62.5 & 500 & 875 & 3500 & 250 & 2000 \\
\hline Klebsiella pneumonia & 62.5 & 500 & 875 & 3500 & 250 & 2000 \\
\hline Proteus mirabilis & 62.5 & 500 & 875 & 3500 & 250 & 1000 \\
\hline
\end{tabular}


the tested bacteria. Antibacterial drug resistance increased rapidly over the past years that emphasizes the need for new strategies (finding new antibacterial drugs or using novel drug delivery systems to enhance drugs efficiency) to overcome these resistances and treat infectious diseases. In this study, a novel drug delivery system, magnetic polymeric nanocomposites, was used to deliver curcumin. As mentioned earlier, the results showed that magnetic polymeric nanocomposites have the capability to enhance the antibacterial effect of curcumin that was consistent with our previous study on nanovesicles of curcumin [42]. According to the CLSI method, the $\mathrm{pH}$ value of the culture medium was between 7.1 and 7.2 that was close to the $\mathrm{pH}$ value of the dissolution medium $(\mathrm{pH}=7.4)$. This can show the correlation between antimicrobial activities and dissolution. According to the CLSI method, the incubation time for bacterial growth is $48 \mathrm{~h}$ and the in vitro release study in $\mathrm{pH} 7.4$ showed that the drug released from nanocomposites during $24 \mathrm{~h}$ and maximum drug released occurred after $24 \mathrm{~h}$. So, the entire entrapped drug is released after $24 \mathrm{~h}$, and by considering bacterial growth time that was $48 \mathrm{~h}$, the effect of the drug and drug release pattern on the bacterial growth can be seen. That can be compared with the pure drug that was used as a control to study nanocomposite effect on the efficacy of the drug. Results in Table 5 show that nanocomposites enhance curcumin efficacy as the values of MIC were decreased from 250 to 62.5 in some bacteria species.

\section{Conclusion}

In the current research, nanocomposites were successfully fabricated and loaded with curcumin using alginate and Iron oxide nanoparticles. The goal was to fabricate magnetic nanocomposites to enrich the efficacy of curcumin against bacteria. The 2 by 3 factorial design was considered for optimization of three independent variables including the alginate concentration, the sonication time, and the curcumin concentration on particle size, PDI, zeta potential, EE\% and DL\% of nanocomposites. This study demonstrated that magnetic nanocomposites of curcumin can improve the effects of curcumin, especially its antibacterial properties, for example, nanocomposite with curcumin has a minimum bactericidal concentration that is 32 times lower than pure curcumin for E. coli. This is remarkable and can have a promising implication in the issue of global microbial resistance to antibiotics.

Author Contribution Zaynab Sadeghi-Ghadi: software, data curation and writing —original draft preparation; Pedram Ebrahimnejad: conceptualization, validation and visualization and supervision; Nicki Behjou: data curation and Writing_original draft preparation, methodology;
Mehrdad Mahkamd: data curation, methodology; Hamid Reza Golie: data curation, methodology; Matthew Lam: writing-reviewing and editing; Ali Nokhodchi: writing—reviewing and editing.

Funding This research was supported by grant number 1554 from the Research Council of Mazandaran University of Medical Sciences.

Data Availability The datasets generated during this work can be available upon request.

\section{Declarations}

Ethics Approval Not applicable.

Consent for Publication All authors are happy with this publication.

Competing Interests The authors declare no competing interests.

Open Access This article is licensed under a Creative Commons Attribution 4.0 International License, which permits use, sharing, adaptation, distribution and reproduction in any medium or format, as long as you give appropriate credit to the original author(s) and the source, provide a link to the Creative Commons licence, and indicate if changes were made. The images or other third party material in this article are included in the article's Creative Commons licence, unless indicated otherwise in a credit line to the material. If material is not included in the article's Creative Commons licence and your intended use is not permitted by statutory regulation or exceeds the permitted use, you will need to obtain permission directly from the copyright holder. To view a copy of this licence, visit http://creativecommons.org/licenses/by/4.0/.

\section{References}

1. Hasan-Nasab B, et al. A promising targeting system to enrich irinotecan antitumor efficacy: folic acid targeted nanoparticles. J Drug Deliver Sci Technol. 2021;102543.

2. Ebrahimnejad P, et al. An updated review of folate-functionalized nanocarriers: a promising ligand in cancer. Drug Discovery Today. 2021.

3. Mohammady H, et al. Encapsulation of irinotecan in polymeric nanoparticles: characterization, release kinetic and cytotoxicity evaluation. Nanomed J. 2016;3(3):159-68.

4. Zhang L, et al. Development of nanoparticles for antimicrobial drug delivery. Curr Med Chem. 2010;17(6):585-94.

5. Sharifi F, Jahangiri M, Ebrahimnejad P. Synthesis of novel polymeric nanoparticles (methoxy-polyethylene glycol-chitosan/hyaluronic acid) containing 7-ethyl-10-hydroxycamptothecin for colon cancer therapy: in vitro, ex vivo and in vivo investigation. Artificial Cells, Nanomedicine, and Biotechnology. 2021;49(1):367-80.

6. Mir M, Ebrahimnejad P. Preparation and characterization of bifunctional nanoparticles of vitamin E TPGS-emulsified PLGAPEG-FOL containing deferasirox. Nanosci Nanotechnol-Asia. 2014;4(2):80-7.

7. Asgarirad $\mathrm{H}$, et al. A promising technology for wound healing; invitro and in-vivo evaluation of chitosan nano-biocomposite films containing gentamicin. J Microencapsul. 2021;38(2):100-7.

8. Salernitano E, Migliaresi C. Composite materials for biomedical applications: a review. J Appl Biomater Biomech. 2003;1(1):3-18.

9. Pradas MM, et al. Interaction between water and polymer chains in poly (hydroxyethyl acrylate) hydrogels. Colloid Polym Sci. 2001;279(4):323-30.

10. Satarkar NS, Hawkins AM, Hilt JZ. Hydrogel nanocomposites in biology and medicine: applications and interactions. In: 
Biological Interactions on Materials Surfaces. Springer; 2009. p. 319-42.

11. Israel LL, et al. Magnetic iron oxide nanoparticles for imaging, targeting and treatment of primary and metastatic tumors of the brain. J Control Release. 2020;320:45-62.

12. Shen L, Li B, Qiao Y. Fe $3 O 4$ nanoparticles in targeted drug/gene delivery systems. Materials. 2018;11(2):324.

13. Coviello T, et al. Polysaccharide hydrogels for modified release formulations. J Control Release. 2007;119(1):5-24.

14. Sonia TA, Sharma CP. An overview of natural polymers for oral insulin delivery. Drug Discovery Today. 2012;17(13-14):784-92.

15. Ebrahimnejad P, Khalili S, Khavarpour M. Survival of Lactobacillus acidophilus as probiotic bacteria using chitosan nanoparticles. Int J Eng. 2017;30(4):456-63.

16. Baysal K, et al. Chitosan/alginate crosslinked hydrogels: preparation, characterization and application for cell growth purposes. Int J Biol Macromol. 2013;59:342-8.

17. Rafi AA, Mahkam M. Preparation of magnetic $\mathrm{pH}$-sensitive microcapsules with an alginate base as colon specific drug delivery systems through an entirely green route. RSC Adv. 2015;5(6):4628-38.

18. Lin J, et al. Preliminary screening of some traditional Zulu medicinal plants for anti-inflammatory and anti-microbial activities. J Ethnopharmacol. 1999;68(1-3):267-74.

19. Shahnia M, Khaksar R. Antimicrobial effects and determination of minimum inhibitory concentration (MIC) methods of essential oils against pathogenic bacteria. Iranian J Nutri Sci Food Technol. 2013;7(5):949-55.

20. Anand P, et al. Bioavailability of curcumin: problems and promises. Mol Pharm. 2007;4(6):807-18.

21. Zheng D, et al. Antibacterial mechanism of curcumin: a review. Chem Biodiver. 2020;17(8):e2000171.

22. Yen C-L, et al. Targeted delivery of curcumin rescues endoplasmic reticulum-retained mutant NOX2 protein and avoids leukocyte apoptosis. J Immunol. 2019;202(12):3394-403.

23. Kazemi S, et al. The synthesis and characterization of targeted delivery curcumin using chitosan-magnetite-reduced graphene oxide as nano-carrier. Int J Biol Macromol. 2021;186:554-62.

24. Maradana MR, Thomas R, O'Sullivan BJ. Targeted delivery of curcumin for treating type 2 diabetes. Mol Nutr Food Res. 2013;57(9):1550-6.

25. Liu X, et al. Preparation of superparamagnetic Fe3O4@ alginate/ chitosan nanospheres for Candida rugosa lipase immobilization and utilization of layer-by-layer assembly to enhance the stability of immobilized lipase. ACS applied materials interfaces. 2012;4(10):5169-78.

26. Taleghani AS, et al. Adsorption and controlled release of ironchelating drug from the amino-terminated PAMAM/ordered mesoporous silica hybrid materials. J Drug Delivery Sci Technol. 2020;56:101579.

27. Ghadi ZS, et al. Preparation, characterization and in vivo evaluation of novel hyaluronan containing niosomes tailored by
Box-Behnken design to co-encapsulate curcumin and quercetin. Eur J Pharm Sci. 2019;130:234-46.

28. Stueber DD, et al. Magnetic nanoparticles in biology and medicine: past, present, and future trends. Pharmaceutics. 2021;13(7):943.

29. Fatima H, Charinpanitkul T, Kim K-S. Fundamentals to apply magnetic nanoparticles for hyperthermia therapy. Nanomaterials. 2021;11(5):1203.

30. Shabestari Khiabani S, et al. Magnetic nanoparticles: preparation methods, applications in cancer diagnosis and cancer therapy. Artificial Cells, Nanomed Biotechnol. 2017;45(1):6-17.

31. Xu C, et al. Applications of iron oxide-based magnetic nanoparticles in the diagnosis and treatment of bacterial infections. Frontiers in bioengineering and biotechnology. 2019;7:141.

32. Pera NP, et al. Detection of pathogenic Streptococcus suis bacteria using magnetic glycoparticles. Org Biomol Chem. 2010;8(10):2425-9.

33. Le TN, Tran TD, Kim MI. A convenient colorimetric bacteria detection method utilizing chitosan-coated magnetic nanoparticles. Nanomaterials. 2020;10(1):92.

34. Riyajan S.-A, Nuim J. Interaction of green polymer blend of modified sodium alginate and carboxylmethyl cellulose encapsulation of turmeric extract. Internatl J Polym Sci. 2013.

35. Esmaili SK, et al. Design, fabrication and characterization of pectin-coated gelatin nanoparticles as potential nano-carrier system. J Food Biochem. 2018; e12729.

36. Sadeghi-Ghadi $Z$, et al. Improved oral delivery of quercetin with hyaluronic acid containing niosomes as a promising formulation. J Drug Target. 2021;29(2):225-34.

37. Ranjan AP, et al. Scale up, optimization and stability analysis of curcumin C3 complex-loaded nanoparticles for cancer therapy. J Nanobiotechno. 2012;10(1):38.

38. Anitha A, et al. Preparation, characterization, in vitro drug release and biological studies of curcumin loaded dextran sulphate-chitosan nanoparticles. Carbohyd Polym. 2011;84(3):1158-64.

39. You J-O, et al. Preparation of regular sized Ca-alginate microspheres using membrane emulsification method. J Microencapsul. 2001;18(4):521-32.

40. Asgari S, Fakhari Z, Berijani S. Synthesis and characterization of $\mathrm{Fe} 3 \mathrm{O} 4$ magnetic nanoparticles coated with carboxymethyl chitosan grafted sodium methacrylate. 2014.

41. dos Santos Araújo P, et al. Thermal degradation of calcium and sodium alginate: a greener synthesis towards calcium oxide micro/ nanoparticles. Int J Biol Macromol. 2019;140:749-60.

42. Sadeghi-Ghadi $Z$, et al. Potent in vitro activity of curcumin and quercetin co-encapsulated in nanovesicles without hyaluronan against Aspergillus and Candida isolates. J de Mycologie Méd. 2020;30(4):101014.

Publisher's Note Springer Nature remains neutral with regard to jurisdictional claims in published maps and institutional affiliations. 